\title{
LA POLÍTICA PÚBLICA DE CUOTA DE EMPLEO PARA PERSONAS CON DISCAPACIDAD EN COSTA RICA
}

\section{PUBLIC POLICY ABOUT EMPLOYMENT SHARE FOR PEOPLE WITH DISABILITIES IN COSTA RICA}

\author{
Allan Abarca* \\ Esteban Arias**
}

\begin{abstract}
RESUMEN
Las personas con discapacidad son habitualmente afectadas por una discriminación en su derecho al trabajo. Asimismo, existe en el imaginario colectivo la creencia de que estas personas no pueden trabajar o que lo harán con menor productividad, también se da un desconocimiento o rechazo al momento de adaptar las pruebas de acceso y de ajustes eventuales al entorno laboral. Esto ha motivado la creación de una variedad de políticas públicas de inserción laboral, una de las cuales es la obligatoriedad de una cuota de plazas para estas personas. Este artículo se basa en una investigación respecto a la toma de decisión de una política de cuotas de empleo en Costa Rica, legislado en el 2010. A partir de un contexto normativo y breve repaso de la amplia experiencia internacional sobre este tipo de política, se realiza una síntesis del diseño de la política respectiva en Costa Rica.
\end{abstract}

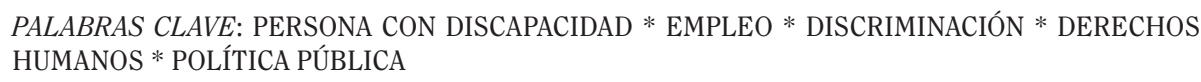

\section{ABSTRACT}

People with disabilities are normally affected by discrimination in their right to work. There is a mixture of social imaginaries around the idea that these people are not able to perform a job, or that they would do it less productively. There is also a great deal of ignorance around the subject, and a rejection of the need to adapt the admission tests or eventually the facilities in the working space. This has led to the creation of a variety of public policies of professional integration, one of which is the obligation to have a share of positions for the people with disabilities. This article is grounded on a research towards the decision making of one policy of employment share in Costa Rica, which was legislated in

\footnotetext{
* Maestría en Salud Pública, Maestría Centroamericana en Ciencias Políticas y Maestría en Administración Universitaria de la Universidad de Costa Rica (UCR). allanabarca@gmail.com (CATIE). earias@catie.ac.cr
} 
2010. From the normative context and a brief review of the wide international experience with this kind of policy, a synthesis is made of the policy design in Costa Rica.

KEYWORDS: PERSON WITH DISABILITIES * EMPLOYMENT * DISCRIMINATION * HUMAN RIGHTS * PUBLIC POLICY

\section{INTRODUCCIÓN}

El trabajo es un satisfactor que cumple con necesidades que van más allá de la mera subsistencia; puede incluir el cumplimiento de la protección, la participación, la identidad, la libertad y la creación (Max-Neef, 1998); por eso es evidente que las barreras al acceso laboral para las personas con discapacidad (PCD) son una discriminación al disfrute de un derecho humano fundamental. La exclusión laboral genera: a) repercusión en la condición de vida propia y familiar (posiblemente, desmejora la calidad de alimentación, educación, la oportunidad de recreación y otros bienes de capital social) y b) impacta negativamente, el estado psicológico y social (se le niega la realización personal que implica tener un empleo y las interacciones sociales que de este se desprenden).

En el año 2011, la Organización Mundial de la Salud (омs) y el Banco Mundial (вм) publican el Primer Informe Mundial Sobre Discapacidad, allí se destaca la imperiosa necesidad de legislar, como una ruta válida y necesaria, a efectos de constituir políticas públicas vigorosas en el tema de discapacidad. Señala que la legislación debe favorecer la no discriminación en las fuentes de empleo, particularmente al exigir a los patronos las adaptaciones razonables en procedimientos de selección y de contratación, adaptar el entorno del trabajo, la modificación de horarios laborales y la proporción de tecnologías auxiliares (2011: 14-17).

En Costa Rica, según análisis efectuados en el censo del año 2000, casi el 95\% de las personas con discapacidad que pueden trabajar y están dispuestos ( $\mathrm{PEA}$ ), se encontraba en condición de desempleo o subempleo (ops, 2004).

En medio de esta situación, luego de varios intentos que se remontan al propio mo- mento de discusión y trámite de la Ley de Igualdad de Oportunidades para las Personas con Discapacidad (Ley 7600), que desde el año 1996, se constituye en el catálogo de Derechos Fundamentales de esta población en Costa Rica, emerge en el año 2010, la Ley de Inclusión y Protección Laboral de las Personas con Discapacidad en el Sector Público, que especifica una cuota de vacantes de al menos un 5\%.

\section{CONTEXTO NORMATIVO}

El derecho a la incorporación laboral de las PCD en Costa Rica recibe un fuerte impulso, desde el punto de vista normativo, con la promulgación de la Ley de Igualdad de Oportunidades para las Personas con Discapacidad (Ley 7600, 1996), cuando estipula que el Estado garantizará el derecho a un empleo adecuado a las condiciones $y$ necesidades personales (art. 23). Incluso, se consigna como un acto de discriminación los mecanismos de selección de personal no adaptados a las condiciones de los aspirantes, el exigir requisitos adicionales y el no emplear a una persona en razón de su discapacidad (art. 24). Finalmente, señala que el Estado ofrecerá asesoría técnica a los empleadores para que adapten el entorno a las condiciones $y$ necesidades de las PCD, lo cual incluye ayudas técnicas y servicios de apoyo (art. 26).

Así, esta norma, pionera en la región Latinoamericana en materia de tutela de derechos humanos de las personas con discapacidad, engendró desde su proceso de formación y trámite, la discusión sobre el empleo de las $\mathrm{PCD}$ como derecho fundamental, pero no se concretaron procedimientos, responsabilidades, cuotas u otras medidas afirmativas de promoción del empleo. 
Como se ha podido comprobar con el tiempo, el impacto de esta ley y sus disposiciones particulares ha sido más enunciativo que real; por un lado, debido a la carencia de disposiciones más concretas en algunos temas como lo es precisamente el de empleo y por el otro, la falta de sanciones en casos de incumplimiento de la norma, siendo esta la crítica más importante hasta la fecha.

En 1999, en el seno de la Organización de Estados Americanos, se promulga la Convención Interamericana para la Eliminación de Todas las Formas de Discriminación Contra las Personas con Discapacidad (Costa Rica la ratifica ese mismo año mediante la Ley 7948). El art. 3 solicita adoptar medidas, entre otros, en el ámbito laboral, para eliminar la discriminación sobre las personas con discapacidad.

En el año 2001, se emite en Ginebra el Repertorio de Recomendaciones Prácticas Sobre la Gestión de las Discapacidades en el Lugar de Trabajo de la Organización Internacional del Trabajo (огт), en el cual se define a la PCD, en estrecha relación al cercenamiento al trabajo: "un individuo cuyas posibilidades de obtener empleo, reintegrarse y conservar un empleo adecuado, así como de progresar en el mismo, resulten considerablemente reducidas como consecuencia de una disminución física, sensorial, intelectual o mental debidamente reconocida" (2001: 5).

Por otra parte, en el año 2007, la Asamblea General de Naciones Unidas promulga la Convención sobre los Derechos de las Personas con Discapacidad y su Protocolo, en lo que ha venido a constituir la conquista teórica y normativa más importante de las PCD a nivel planetario, desde que el tema de la discapacidad se ha planteado como un asunto de respeto a derechos fundamentales $y$ prácticamente, desde el surgimiento del Derecho Internacional de los Derechos Humanos. Esto se explica por la moderna visión de la discapacidad que propone, la importancia de enfocar el tema como un asunto social de interés público global $y$ las responsabilidades que encomienda a los actores del Derecho Internacional como Estados y de la misma Organización de las Naciones Unidas (onu).

En el caso de Costa Rica, su ratificación se convierte en Ley 8661, en el año 2008; en esta se advierten varias consideraciones sobre el acceso al trabajo:

a) Convoca a los Estados a comprometerse en "promover el reconocimiento de las capacidades, los méritos y las habilidades de las personas con discapacidad $y$ de sus aportaciones en relación con el lugar de trabajo y el mercado laboral” (art. 8).

b) Solicita un compromiso a reconocer "el derecho de las personas con discapacidad a trabajar, en igualdad de condiciones con las demás; ello incluye el derecho a tener la oportunidad de ganarse la vida mediante un trabajo libremente elegido o aceptado en un mercado $y$ un entorno laboral que sea abierto, inclusivo $y$ accesible a las personas con discapacidad" (art. 27). Por eso llama a legislar, entre otros, para prohibir la discriminación en los empleos (incluida las condiciones de selección) y de "emplear a personas con discapacidad en el sector público" (art. 27).

De estas disposiciones, es evidente el importante papel que las Naciones Unidas reunidas en su Asamblea General, le otorgan al empleo de las PCD, al otorgarles un rango de derecho fundamental para su desarrollo pleno como individuos en igualdad de oportunidades con el resto de la sociedad. También destaca el interés $y$ peso que la misma Organización deposita en los Estados y las sociedades, para el cumplimiento, respeto y desarrollo de este derecho a partir de sus propias normativas internas y sus mecanismos nacionales de promoción de derechos.

Ahora bien, esta legislación — de generar acceso al empleo de las PCD como un 
derecho humano - tiene como piedra angular una serie de normativas internacionales que inicia con la Declaración Universal de los Derechos Humanos (Asamblea General, onu, 1948), que demanda que toda persona tiene derecho al trabajo, sin discriminación alguna y que la remuneración debe ser equitativa $y$ satisfactoria (art. 23).

En el año 1958 (con la entrada en vigor en Costa Rica en 1960) se dicta el Convenio Relativo a la Discriminación en Materia de Empleo y Ocupación, conocido como el Convenio 111 de la orт. En esto interesa destacar la obligación de los Estados en "formular y llevar a cabo una política nacional que promueva, por métodos adecuados a las condiciones y a la práctica nacionales, la igualdad de oportunidades $y$ de trato en materia de empleo y ocupación, con objeto de eliminar cualquier discriminación a este respecto" (art. 2).

Posteriormente, en el año 1971, se emite la Declaración de los Derechos del Retrasado Mental (Naciones Unidas); el punto 3 afirma que este "tiene derecho, en la medida de sus posibilidades, a desempeñar un empleo productivo o alguna otra ocupación útil". En similar forma se manifiesta la Declaración de los Derechos de los Impedidos; en su enunciado 7 especifica que el impedido "tiene derecho, en la medida de sus posibilidades, a obtener $y$ conservar un empleo y a ejercer una ocupación útil, productiva y remunerativa" (1975).

Un nuevo convenio de la ort se emite en el año 1983 (en vigencia desde 1985 en Costa Rica), el Convenio sobre la Readaptación Profesional y el Empleo de Personas Inválidas, conocido como el Convenio 159 (luego ratificado en la Ley 7219). El art. 2 señala la obligación de los países a formular, aplicar y revisar periódicamente la política nacional sobre la readaptación profesional y el empleo de "personas inválidas". Asimismo, demanda que las autoridades generen medidas para la generación de empleo (art. 7).

En 1993, las Naciones Unidas emiten las Normas Uniformes sobre la Igualdad de
Oportunidades para las Personas con Discapacidad, sentencia que "los Estados deben reconocer el principio de que las personas con discapacidad deben estar facultadas para ejercer sus derechos humanos, en particular en materia de empleo" (art. 7). Para eso demanda emitir disposiciones legislativas y reglamentarias, así como, exige el apoyo al mercado de trabajo, utilizando, entre otras medidas, los planes de cuotas basadas en incentivos. Agrega que "en su calidad de empleadores, los Estados deben crear condiciones favorables para el empleo de personas con discapacidad en el sector público" (art. 7).

\section{CUOTAS DE EMPLEO EN LA EXPERIENCIA INTERNACIONAL}

En el año 2010, la ley introducida en Costa Rica, se califica como una política pública de transferencia (policy transfer): modelo de toma de decisiones que emerge en la década de los 80 y que significa copiar o adaptar diseños de política desarrollados en otros espacios geográficos, que se consideren necesarios y pertinentes para el ámbito nacional.

La estrategia de cuotas de empleo como parte de una política para la empleabilidad de PCD surge en 1919, luego de la Primera Guerra Mundial, cuando Alemania y Austria lo desarrollan para brindar empleo a personal militar que adquiere una discapacidad (Laloma, 2007). Posteriormente, en 1944, en Inglaterra se establece que toda empresa privada con al menos 20 personas debía tener el 3\% reservado para personas con discapacidad y dicta un plan de ocupaciones reservadas (ascensoristas y cuidadores de carros) (O’Reilly, 2003).

\section{EXPERIENCIA INTERNACIONAL}

La diversidad en las políticas de cuotas es amplia: hay casos en que la cuota se revisa cada cierto tiempo o es fija; es uniforme para todo el país o difiere según la zona geográfica; instituye una cuota uniforme o esta varía según el número de empleados de la organización. También 
hay variantes en las sanciones por incumplimientos (se aplican multas, impuestos, se dan a conocer públicamente los incumplimientos o simplemente no hay sanciones), también es posible hallar la generación de diversos incentivos para las organizaciones que sobrepasen las metas de contratación (exoneraciones, recompensas económicas, entre otros).

En otros países, el sistema de cuotas se aplica en: Alemania, Francia, Italia, Austria, Polonia, Corea, República Checa, Hungría, Rumania, Rusia, República Eslovaca, Irlanda, Bélgica, España, Grecia, Luxemburgo, Reino Unido, Vietnam, Túnez, Pakistán, Marruecos, Azerbaiyán, China, India, Japón, Mongolia, Filipinas, Sri Lanka, Tailandia, Etiopía, Mauricio, Tanzania y Kuwait ( O'Reilly, 2003; Mont, 2004 y Monzón, 2008).

En América Latina, la legislación de cuota laboral es amplia, preponderantemente fijada para el sector público e incluye una diversidad de planteamientos: Ecuador (se obliga en $4 \%$ al empleador público o privado que cuente con un mínimo de veinticinco trabajadores), El Salvador (mínimo 1 persona por cada 25 trabajadores), Panamá ( $2 \%$ del personal en organizaciones con 50 personas o más), $\mathrm{Pa}$ raguay (5\% del personal en el sector público), Perú (3\% del total del personal), Argentina (5\% del personal), Bolivia (5\% en sector público de vacantes), Brasil (a partir de 100 empleados en empresas privadas, entre un $2 \%$ y $5 \%$ dependiendo del número de trabajadores), Uruguay (4\% de las vacantes), Venezuela (5\% de nómina de empleados), Honduras (dependiendo del número de empleados, por ejemplo, $3 \%$ si se tiene de 75 a 99 trabajadores) (Asociación Latinoamericana de Abogados para la Protección y Defensa de los Derechos Humanos, 2010 y Murray-Heron, 2003).

Ahora bien, los casos paradigmáticos en sistema de cuotas son España y Japón.

\section{CASO DE ESPAÑA}

En 1982, en España se promulga la Ley de Integración Social de los Minusválidos (LISMI) que regula la incorporación laboral de las personas con discapacidad e incluye las adaptaciones de los entornos, cuando así se requiera, tratando de generar lo más pronto posible la transición a un puesto de trabajo normalizado (Laloma, 2007). El art. 38 señala que "las empresas públicas y privadas que empleen a un número de 50 o más trabajadores vendrán obligadas a que de entre ellos, al menos, el 2 por 100 sean trabajadores minusválidos" (Ley 13/1982, España). Un Real Decreto del año 2000 (N.27/2000) flexibilizaría la exigencia de cuota, especificando la forma en la cual una organización podía justificar el incumplimiento de la medida, respondiendo a través de una serie de medidas alternativas (Laloma, 2007). El carácter de excepcionalidad se completa en el 2005, regulando con la petición de informes técnicos detallados, en los cuales se corrobora esa imposibilidad de contratación.

De nuevo en el tema de cuotas, desde el año 1998, se genera una disposición de reserva de plazas centrado en el sector público (Ley 23/1988, 28 de julio), en el cual se estipula "no inferior al 3\% de las vacantes para ser cubierta entre personas con discapacidad de grado igual o superior al 33\%, de modo que progresivamente se alcance el dos por ciento de los efectivos totales de la Administración del Estado", siempre que superen las pruebas selectivas. Una nueva disposición del año 2003 eleva al 5\% ese cupo (Ley 53/2003, España).

\section{CASO DE JAPÓN}

En 1960, se promulga la Ley de Promoción de Empleo para personas con Minusvalía, la cual establece un sistema de cuotas que incluía asistencia financiera y un sistema de apoyo a los ajustes; se ofreció por medio de 600 oficinas públicas y sucursales. Pero fue en el año 1976 que adquiere notoriedad: las empresas que no cumplen se les obliga a presentar un plan para el empleo $y$ en caso de no cumplimiento, hay posibilidad de revelar nombres a la ciudadanía como un mecanismo de denuncia ante actitudes negativas (Matsui, 1998). 
El actual sistema japonés es diverso: constantemente las cuotas son revisadas y ajustadas, estas varían según el tipo de organización y hay posibilidad de contabilizar doble a personas con discapacidad severa (Yasui, 1995 y Kudo, 2010).

A partir del análisis de datos de la última década, T. Kudo asegura que el sistema de cuotas de empleo en Japón ha generado un incremento mayor de la tasa de personas empleadas en comparación con la Ley Anti Discriminación de los Estados Unidos (Congreso de los Estados Unidos de América, 26/07/1990: 19). No obstante, Hasegawa (2007) indica que si bien, el sistema japonés ha sido capaz de asegurar efectos positivos dentro de ciertos parámetros, lo ha hecho con una perspectiva inadecuada sobre la igualdad de trato de las personas con discapacidad, entre otros aspectos deficitarios.

\section{EL CASO DE COSTA RICA}

La actual política atraviesa una interesante fase de formulación que inicia en el año 2006 y culmina en su diseño de operacionalización en el año 2011. En el diagrama se puede comprender lo que se denomina como 2 fases de formulación y 4 episodios de tomas de decisión formal (ver imagen 1). Un aspecto importante fue el respaldo político de varias fracciones legislativas representadas en la Comisión de Asuntos Sociales (que conoció el proyecto original) y el respaldo de las instituciones consultadas, particularmente de la Procuraduría General de la República (PGR) que en su dictamen, apoya la sustentabilidad jurídica de la política y su legitimidad al amparo de los derechos humanos (PGR, Opinión Jurídica 060-J, 2007). 


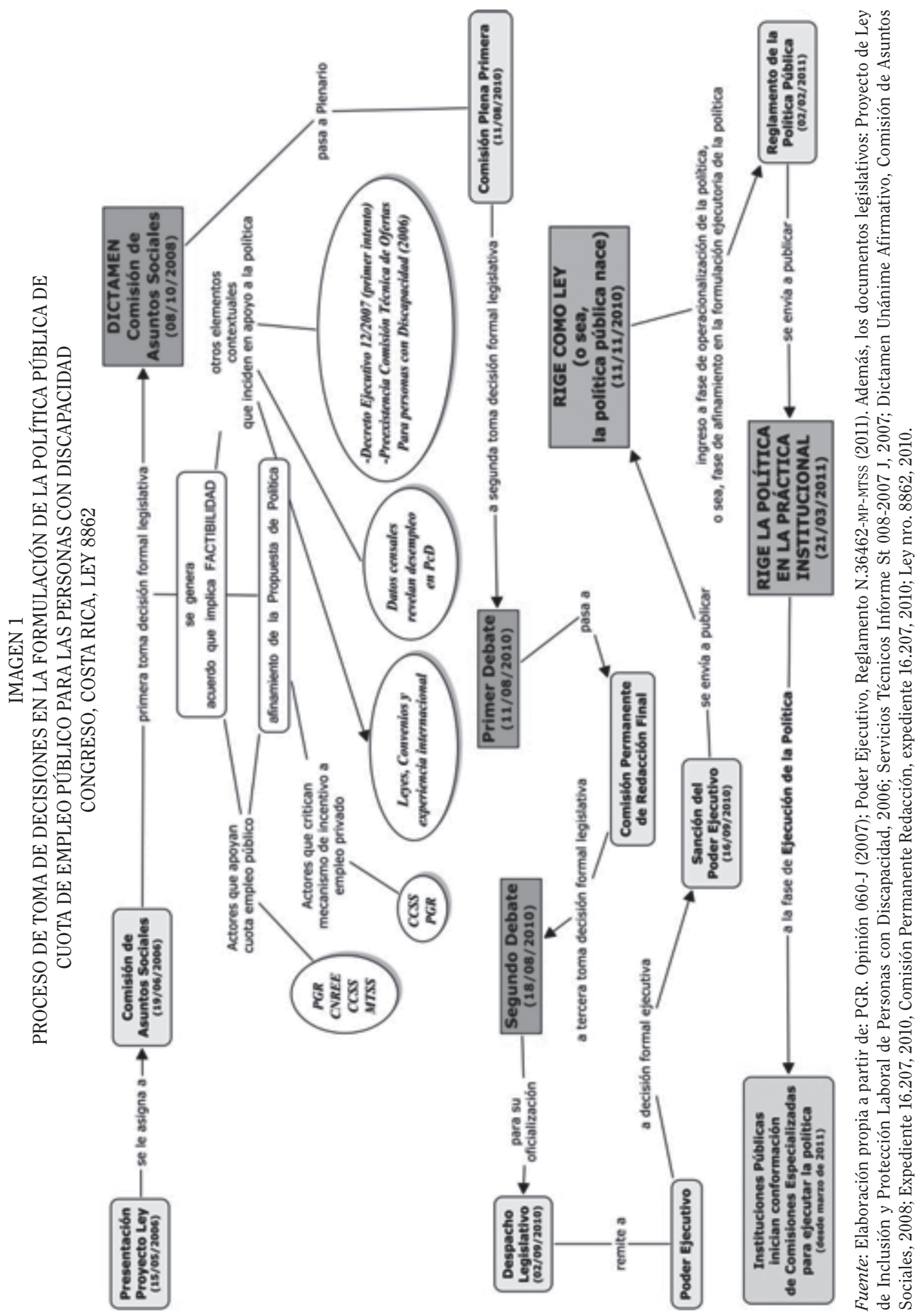

Rev. Ciencias Sociales Universidad de Costa Rica, 146: 13-25 / 2014 (IV). (ISSN: 0482-5276) (c) (1) () 
La propuesta de política original (2006) tiene dos componentes. En primer lugar, estipula la reserva del 5\% de empleo público para las personas con discapacidad (PCD) y en segundo lugar, el incentivo de no pago de cargas laborales para las empresas que contraten a PCD. Este segundo punto fue eliminado esencialmente por falta de claridad en el mecanismo y por los efectos dañinos que podría causar en otro tipo de servicios sociales (que esencialmente administra la ccss).

La decisión adoptada es la que estipula una cuota en cada institución del sector público por año para las PCD; incluso la propuesta es mejorada en 3 aspectos:

a) En vez de una cuota del 5\% queda señalado "al menos un 5\%"; con lo cual se fija un piso de incorporación laboral para PCD.

b) Se sustituye "sector público" por "en cada uno de los Poderes"; con esto se evita la ambigüedad de si se abarca o no al sector público descentralizado, lo cual pudo haber exigido una consulta a cada institución descentralizada so pena de incurrir en actos de inconstitucionalidad.

c) Se agrega la restricción que la política opera "siempre que exista oferta de empleo".

Así, en agosto de 2010, se promulga la Ley de Inclusión y Protección Laboral de las Personas con Discapacidad en el Sector Público. Como menciona su artículo único:

En las ofertas de empleo público de los Poderes del Estado se reservará cuando menos un porcentaje de un cinco por ciento (5\%) de las vacantes, en cada uno de los Poderes, para que sean cubiertas por personas con discapacidad siempre que exista oferta de empleo y se superen las pruebas selectivas y de idoneidad, según lo determine el régimen de personal de cada uno de esos Poderes (Asamblea Legislativa de la República de Costa Rica, 11/11/2010).

El sistema de cuota de empleo en Costa Rica, lamentablemente excluyó la posibilidad de aplicarlo al sector privado, dado que el legislador se preocupó más por un incentivo de contratación inviable (exonerar cargas sociales) que por hacerlo obligatorio, valorando otros posibles incentivos o estímulos para la contratación. En todo caso -y siempre sobre el artículo del proyecto de ley que pretendía ampliar la cuota al sector privado- un error de cálculo político fue el considerar una cuota fija y relativamente alta al inicio, en vez de optar por una cuota progresiva en el tiempo, según tipo de sector y dependiendo de un número mínimo de trabajadores. Esos elementos le pudieron haber dado viabilidad a una aplicación en el sector privado.

Finalmente, en marzo de 2011, rige el Reglamento (mediante el Decreto Ejecutivo nro. 36462) y con esto se perfila la fase de operacionalización de la política, la cual exige la intervención de cuatro comisiones. Dos de estas existen por dos políticas públicas que para otros efectos se constituyeron con anterioridad: la Comisión Institucional en Materia de Discapacidad (2001) y la Comisión Técnica Interinstitucional para la Empleabilidad de Personas con Discapacidad (2006); las otras dos son creadas a propósito de esta ley, la Comisión Especializada y la Comisión Técnica de Ofertas para Personas con Discapacidad (2011). Cada una de las cuatro comisiones tiene distintos grados de responsabilidad obligada o posible, en la ejecutividad de la política (ver tabla 1). 


\section{TABLA 1 \\ COMISIONES INTERVINIENTES EN LA OPERACIONALIZACIÓN \\ DE LA POLÍTICA PÚBLICA DE PROTECCIÓN LABORAL DE LAS PERSONAS CON DISCAPACIDAD EN EL SECTOR PÚBLICO, COSTA RICA}

\begin{tabular}{|c|c|c|}
\hline COMISIÓN & DEFINICIÓN & RESPONSABILIDADES \\
\hline $\begin{array}{l}\text { Comisión } \\
\text { Especializada }\end{array}$ & $\begin{array}{l}\text { Cada institución pública debe tener su propia } \\
\text { comisión, nombrada por el jerarca. } \\
\text { La integra el Director de Recursos Humanos } \\
\text { (coordinador), un representante del cImAD } \\
\text { y un especialista en terapia ocupacional } \\
\text { (preferiblemente) o un psicólogo. } \\
\text { Debe velar por el cumplimiento de la aplicación } \\
\text { del Reglamento. }\end{array}$ & $\begin{array}{l}\text {-Cada año realiza un estudio para identificar } \\
\text { los puestos que serán objeto de reserva. } \\
\text {-Informa al jerarca institucional del resultado } \\
\text { del estudio, identificando las posibles plazas } \\
\text { vacantes a reservar para las PCD. } \\
\text {-Recomienda al jerarca las adecuaciones y } \\
\text { adaptaciones pertinentes para ser aplicadas en } \\
\text { el proceso de evaluación y contratación. } \\
\text {-Da seguimiento a la contratación y la } \\
\text { respectiva inserción en el ámbito laboral. }\end{array}$ \\
\hline $\begin{array}{l}\text { Comisión Técnica } \\
\text { Interinstitucional } \\
\text { para la } \\
\text { Empleabilidad } \\
\text { de Personas con } \\
\text { Discapacidad }\end{array}$ & $\begin{array}{l}\text { Órgano compuesto por representantes de } \\
\text { varias instituciones y organizaciones que debe: } \\
\text { asesorar y coordinar con la Secretaría Técnica } \\
\text { del Consejo Nacional de Intermediación de } \\
\text { Empleo, las acciones de empleabilidad de las } \\
\text { PCD; evaluar programas y acciones de empleo } \\
\text { que se realizan en el país; promover proyectos } \\
\text { de creación de empleo; coordinar acciones de } \\
\text { asesoría y de capacitación a empleadores del } \\
\text { sector público y privado, entre otros. }\end{array}$ & $\begin{array}{l}\text {-Recibe de los Departamentos de RRHH de } \\
\text { las instituciones públicas, informes de } \\
\text { cumplimiento semestral, con el detalle de } \\
\text { las acciones realizadas y las justificaciones } \\
\text { pertinentes. Los informes se presentan a más } \\
\text { tardar el } 31 \text { de julio y el } 31 \text { de enero de cada } \\
\text { año. } \\
\text {-Define los lineamientos y los formatos de los } \\
\text { informes de cumplimiento que presentan las } \\
\text { instituciones. } \\
\text {-Debe analizar y revisar los informes de } \\
\text { cumplimiento semestral, a fin de emitir las } \\
\text { observaciones, recomendaciones técnicas } \\
\text { y directrices tendientes a mejorar la } \\
\text { empleabilidad de las PCD en el sector público. } \\
\text {-Gestar la articulación con las entidades } \\
\text { públicas pertinentes, a fin de crear una } \\
\text { oferta educativa y de formación técnica, de } \\
\text { acuerdo a las necesidades de la población con } \\
\text { discapacidad, de tal manera que se promueva la } \\
\text { empleabilidad de esta población. }\end{array}$ \\
\hline $\begin{array}{l}\text { Comisión } \\
\text { Institucional } \\
\text { en Materia de } \\
\text { Discapacidad } \\
\text { (CIMAD) } \\
\end{array}$ & $\begin{array}{l}\text { Órgano que debe funcionar en cada institución. } \\
\text { Su propósito esencial es que los servicios sean } \\
\text { accesibles para todas las personas. }\end{array}$ & $\begin{array}{l}\text { Uno de sus miembros se integra a la Comisión } \\
\text { Especializada. }\end{array}$ \\
\hline $\begin{array}{l}\text { Comisión Técnica } \\
\text { de Ofertas para } \\
\text { Personas con } \\
\text { Discapacidad (СTOPD) }\end{array}$ & $\begin{array}{l}\text { Órgano colegiado especializado en el } \\
\text { reclutamiento y selección de PCD que opera en } \\
\text { la Dirección General de Servicio Civil (DGSC), } \\
\text { integrado por los representantes del CNREE y de } \\
\text { la DGSC. }\end{array}$ & $\begin{array}{l}\text { Las Comisiones Técnicas pueden acudir para } \\
\text { asesorarse sobre las adecuaciones que se } \\
\text { necesitan en el proceso de selección y para } \\
\text { valorar la idoneidad en el desempeño de los } \\
\text { cargos. }\end{array}$ \\
\hline
\end{tabular}

Notas:

La CIMAD es creada mediante Directriz Presidencial nro. 27 del 30 de enero de 2001.

La CTOPD fue creada mediante Directriz 014-MTSS del 20 de noviembre de 2006.

Fuente: $\quad$ Elaboración propia, con base en: los arts. 1, 4, 7, 9, 12 y 13 del Reglamento Decreto Ejecutivo nro. 36462 y del Reglamento Ley nro. 8661, 2008, la Directriz 014-MTss, 2006 y el Poder Ejecutivo, Directriz Presidencial nro. 27, publicado en La Gaceta 21, 2001. 
Dado lo reciente de la normativa es imposible realizar una evaluación de impacto o de resultado; además, un elemento circunstancial que a febrero del año 2012, ha frenado su ejecución, ha sido el decreto sobre el congelamiento de plazas del sector público dictado como medida de austeridad, desde el primer bimestre del año 2011.

En general, la arquitectura de la política pública acusa un buen diseño para su operacionalización, aunque existen tres nudos críticos específicos:

a) El primer nudo crítico es la Comisión Especializada instaurada en cada institución pública, ya que de esta se desprenden las voluntades $y$ acciones de reserva debidamente planeadas. En esta, la transparencia en la información sobre plazas y disponibilidad de puestos de trabajo es fundamental, porque solo al interior de cada institución se tendrá seguridad del cumplimiento efectivo de la norma.

b) El segundo nudo crítico subyace en la Comisión Técnica de Empleabilidad ya que buena parte del éxito en la operacionalización de la política, depende de su capacidad resolutiva. Al respecto, se señala la importancia de que la Comisión participe a las personas con discapacidad en sus procesos, en aras de mantener vigencia $y$ pertinencia en su trabajo, relacionando personas con discapacidad con oportunidades de empleo.

c) El tercer nudo crítico recae en la responsabilidad $y$ sentido proactivo que desempeñe el Consejo Nacional de Rehabilitación y Educación Especial (CNREE) — ente rector de la materia- particularmente, en la vigilancia o fiscalización de la buena marcha de la política. Para muchos, sobre este punto podría realizarse todo un análisis que pasa por discutir la urgente necesidad de reformar al CNREE y la normativa que lo rige, vista su probada incapacidad actual por atender las exigencias que implica ser el ente rector en temas de discapacidad.
Es evidente que mucha de la eficacia eventual de la política está depositada en resolver las potenciales dificultades señaladas (nudos) y de superar el reto histórico de la administración pública, que es la burocracia excesiva y la falta de pertinencia en tiempo $y$ forma, del trabajo institucional, frente a las necesidades de los administrados.

Por otra parte, la voluntad política por promover la empleabilidad de las personas con discapacidad o de respetar sus demás derechos, es un requisito indispensable para el éxito de esta política, pero no depende únicamente de la existencia de una norma o un andamiaje institucional. Se trata más bien de un reto cultural de educación/reeducación de la sociedad en su conjunto $y$ por su envergadura, es claro que no puede ser asumido $y$ enfrentado solamente por el sector público de empleo, lo que implica niveles de coordinación social y política de alto nivel, que superan las posibilidades de trabajo de una sola institución, de aquí la urgencia de discutir el papel del CNREE.

Por otra parte, dejar de lado la posibilidad de que el empleador privado también participe del empleo de personas con discapacidad, es una gran carencia de la política costarricense comentada, porque mucho del cambio cultural $y$ la reeducación social que se debe promover, a la luz del respeto por la diversidad y la diferencia como riquezas de una sociedad, pasa por la convivencia directa de las personas con discapacidad en igualdad de condiciones en todas las dinámicas sociales con el resto de la población. Así, como no era ni puede ser conveniente que se identificara a las personas con discapacidad únicamente como vendedores de lotería o con cualquier otro empleo - sin ninguna alusión peyorativa - tampoco es conveniente que se identifique a las personas con discapacidad únicamente como capaces de trabajar en el sector público, porque es una negación de sus capacidades y una frontera invisible a la igualdad.

En el mismo sentido, la participación laboral de las personas con discapacidad en todas las dimensiones y ocupaciones del espectro, público o privado, es la mejor oportunidad de reeducación de que dispone una sociedad, porque la mayor parte de los temores 
infundados y las actitudes discriminatorias, se fundan en la ignorancia, producto de esa falta de contacto con la diversidad.

\section{CONCLUSIONES}

La investigadora japonesa Hasegawa (2007) señala que existen dos sistemas para propiciar el empleo para las PCD: una, es la de fomentar una legislación antidiscriminatoria $y$ la otra, una legislación que establezca cuotas para estas. Respecto a este último sistema, un amplio examen de la experiencia internacional reporta aspectos positivos y negativos.

De las "políticas de cuotas" sobresalen como elementos negativos los siguientes:

a) No hay país que demuestre haber cumplido con las cuotas impuestas vía legislación.

b) Gran cantidad de empresas prefieren pagar impuestos o multas antes que contratar, aduciendo, cierto o no, la carencia de mano de obra para sus necesidades.

c) No siempre tienen una repercusión de imagen positiva de las PCD al hacer obligatoria su contratación, lo que repercute en más barreras sociales (etiquetamiento).

d) El sistema es altamente restrictivo por la necesidad de definir a una PCD.

Por otra parte, quienes defienden esta política pública aducen:

a) La cuota de empleo efectiva se eleva con esta obligatoriedad.

b) Aún cuando se paguen impuestos o multas, estos financian otros programas $y$ actividades en pro de esa incorporación laboral.

c) Es coincidente con un espíritu de derechos humanos, en tanto genera fuentes de empleo para las PCD, las cuales normalmente son excluidas de sistemas de contratación no por falta de capacidad, sino por discriminación.

d) Es factible en tanto no genera altos costos financieros. Los únicos están dados por la responsabilidad que se le da al Estado de generar acciones de modificación del ambiente laboral.
Entre los aspectos por mejorar o vigilar en la política legislada en Costa Rica están:

a) Hay que atestiguar no solo el cumplimiento de la política (la evaluación de resultados) sino la calidad de los trabajos (la coherencia entre estos y las habilidades de las personas con discapacidad) que oportunamente se generen y su repercusión en la calidad de vida de las PCD contratadas (evaluación de impacto).

b) Se debe insistir en que el éxito de la política depende, entre otros aspectos, de la vigilancia estrecha que realice la "Comisión Técnica Interinstitucional para la Empleabilidad de Personas con Discapacidad" (adscrito al Ministerio de Trabajo), ya que controla los procesos y los cumplimientos de las instituciones públicas. Es indispensable revisar su constitución, capacidades reales y recursos disponibles, debido a que solo la recepción de información que debe realizar dos veces al año podría hacer perder su sentido gestor del proceso. En ese sentido, incluso el cNREE (2009), ha señalado vicios en su previo accionar.

c) Es de esperar que el "Registro Nacional de Estadística sobre Discapacidad (RED)" - dependencia técnica del CNREE, creada en el 2011-genere información compatible con esta política. Además, el éxito de la política estriba también en la capacidad de generar información a las PCD respecto a las plazas en el sector público susceptibles de empleo. En este sentido, le compete al cnReE $y$ al Ministerio de Trabajo estimular $y / 0$ generar una política de promoción e información capaz de llegar a las PCD y de ser sostenible en el tiempo.

d) Resulta imprescindible e impostergable que los grupos $y$ asociaciones entorno a la discapacidad, conozcan y participen activamente de la manera en que esta política se lleva a la práctica, esto para favorecer el control, la transparencia y la rendición de cuentas.

e) Finalmente, la voluntad con mayúscula —política y social— frente a la indiferencia 
que todavía hoy caracteriza el abordaje general de la discapacidad como fenómeno social, es la única fórmula capaz de garantizar la sostenibilidad actual y futura de esta o cualquier otra política pública destinada a promover los derechos fundamentales de las personas con discapacidad. Imprescindible es garantizar, en el mediano y largo plazo, una transformación cultural $y$ una reeducación que permita a la sociedad superar sus complejos y prejuicios en torno a un fenómeno que únicamente es una manifestación más de la diversidad o la variedad, que precisamente es la norma $y$ no la excepción en cualquier sociedad.

\section{BIBLIOGRAFÍA}

\section{LIBROS}

Laloma García, Miguel. Empleo protegido en España. Análisis de la normativa legal y logros alcanzados. España: Ediciones Cinca, 2007.

Max-Neef, Manfred A. Desarrollo a escala humana. Conceptos, aplicaciones y algunas reflexiones. España: Editorial Nordan Comunidad, 1998.

Monzón Campos, José Luis (coord.). Economía social e inserción laboral de las personas con discapacidad en el País Vasco. España: Editorial Biblioteca Nueva, 2008.

Murray, Bárbara y Heron, Robert. La vinculación laboral de las personas discapacitadas que buscan empleo. Elementos para un servicio efectivo. Uruguay: Oficina Internacional del Trabajo-Gladnet Collection, 2003.

Organización Internacional del Trabajo (огт). Repertorio de recomendaciones prácticas sobre la gestión de las discapacidades en el lugar de trabajo. Ginebra, Suiza: orт, 2008.

Organización Mundial de la Salud (омs) y Banco Mundial (вм). "Resumen". Informe Mundial sobre la Discapacidad. República de Malta, 2011.

O'Reilly, Arthur. El derecho al trabajo decente de las personas con discapacidades.
Ginebra, Suiza: Organización Internacional del Trabajo (огт), 2003.

\section{PUBLICACIONES PERIÓDICAS}

Hasegawa, Tamako. "Equality of opportunity or employment quotas? A comparison of Japanese and American employment policies for the disabled". Social Science Japan Journal 1 (10). Japón. Institute de Ciencias Sociales, Universidad de Tokyo, 2007: 41-57.

Kudo, Tadashi. "Japan's employment rate of persons with disabilities and outcome of employment quota system". Japan Labor Review 1 (7). Japón. Instituto de Políticas de Trabajo y Formación, 2010: 1-19.

Matsui, Ryosuke. "An overview of the impact of employment quota system in Japan". Asia Pacific Disability Rehabilitation Journal 1 (9). India. National Printing Press, 1998: 41-57.

Mont, Daniel. "Disability employment policy". Social Protection Discussion Paper Series 413. Washington dc, Eeuv: Banco Mundial (вм), 2004.

OTROS

Asamblea Legislativa de la República de Costa Rica. Comisión Permanente Especial de Redacción. "Expediente nro. 16 207". Proyecto Inclusión y Protección Laboral de las Personas con Discapacidad en el Sector Público. Costa Rica, 2010a.

Asamblea Legislativa de la República de Costa Rica. "Ley nro. 8862. Inclusión y Protección Laboral de las Personas con Discapacidad en el Sector Público". La Gaceta 219. 11 de noviembre de 2010b.

Asamblea Legislativa de la República de Costa Rica. "Ley nro. 8661. Aprobación de la Convención Internacional de Derechos de las Personas con Discapacidad y su Protocolo Facultativo". La Gaceta 187. 29 de setiembre de 2008 .

Asamblea Legislativa de la República de Costa Rica. Departamento de Servicios Técnicos. "Informe sт. 008-2007 J. sobre expediente nro. 16 207”. Ley de Inclusión 
y Protección Laboral de las Personas con Discapacidad en el Sector Público y Privado. Costa Rica, 2007.

Asamblea Legislativa de la República de Costa Rica. "Ley Nro 7600. Ley de Igualdad de Oportunidades para las Personas con Discapacidad". La Gaceta 102. 29 de mayo de 1996.

Asociación Latinoamericana de Abogados para la Protección y Defensa de los Derechos Humanos "Julio Fretes". Informe sobre la Cuota de Contratación a Personas con Discapacidad al Mercado Laboral en los Países de América Latina. En: <http:// discapar.blogspot.com> [consultado el 04 de noviembre de 2011].

Congreso de los Estados Unidos de América. Americans with Disabilities Act. Estados Unidos de América. 26 de julio de 1990.

Consejo Nacional de Rehabilitación y Educación Especial de Costa Rica (CNREE). Informe Anual de Cumplimiento de las Metas Institucionales de las Acciones Estratégicas, contenidas en el Plan Nacional de Desarrollo y del periodo 2006-2010. Documento \#AP-D 003-2010. Costa Rica, 2009.

Ministerio de la Presidencia del Gobierno de España. "Ley nro. 13/1982. Integración Social de Minusválidos". Boletín Oficial del Estado (вов) 103. España, 1982.

Ministerio de la Presidencia del Gobierno de España. "Ley nro. 53/2003. Ley sobre Empleo Público de Discapacitados". Boletín Oficial del Estado (вов) 296. España, 2003.

Ministerio de la Presidencia del Gobierno de España. Real Decreto 2271/2004. Acceso al Empleo Público y la Provisión de Puestos de Trabajo de las Personas con discapacidad. Boletín Oficial del Estado (вов) 303. España, 2004.

Naciones Unidas. Declaración Universal de los Derechos Humanos. París, Francia. 1948.

Naciones Unidas. Declaración de los Derechos del Retrasado Mental. Nueva York, eEvu. 1971.

Naciones Unidas. Declaración de los Derechos de los Impedidos. Nueva York, eeuu. 1975.

Naciones Unidas. Normas Uniformes sobre la Igualdad de Oportunidades para las Personas con Discapacidad. Nueva York, EEUu. 1993.

Naciones Unidas. Convención sobre los Derechos de las Personas con
Discapacidad y su Protocolo. Nueva York, EeUu. 2007.

Organización de Estados Americanos (oea). Convención Interamericana para la Eliminación de Todas las Formas de Discriminación contra las Personas con Discapacidad. Washington, eeuu. 1999.

Organización Internacional del Trabajo (огт). Convenio Relativo a la Discriminación en Materia de Empleo y Ocupación. Convenio nro. 111. Ginebra, Suiza. 1958.

Organización Internacional del Trabajo (огт). Convenio sobre la Readaptación Profesional y el Empleo de Personas Inválidas. Convenio nro. 159. Ginebra, Suiza. 1983.

Organización Panamericana de la Salud. "La discapacidad en Costa Rica: situación actual y perspectivas". Serie Análisis de Situación de Salud 14. Costa Rica, 2004.

Poder Ejecutivo de la República de Costa Rica. "Directriz Presidencial Nro. 27". La Gaceta 21. 30 de enero de 2001.

Poder Ejecutivo de la República de Costa Rica. Decreto Ejecutivo nro. 33135-мр-мтss. Costa Rica, 2007.

Poder Ejecutivo de la República de Costa Rica. "Reglamento a la Ley de Inclusión y Protección Laboral de las Personas con Discapacidad en el Sector Público nro. 36462-мр-мтss". La Gaceta 56. 21 de marzo de 2011.

Procuraduría General de la República. Opinión Jurídica 060-J. Sistema Costarricense de Información Jurídica. Costa Rica, 2007.

Yasui, Shusaku. "Employment Quota System in Japan". Gladnet Collection 83. New York, Estados Unidos: Cornell University ILR School, 1995. En: $<$ http://digitalcommons.ilr.cornell.edu/ gladnetcollect/83> [consultado el 2 de noviembre de 2012].

Fecha de ingreso: 05/08/2013 Fecha de aprobación: 30/01/2014 
